\title{
Kleefstra Syndrome
}

National Cancer Institute

\section{Source}

National Cancer Institute. Kleefstra Syndrome. NCI Thesaurus. Code C129976.

A condition caused by mutation or deletion of the EHMT 1 gene, encoding histone-lysine $\mathrm{N}$-methyltransferase EHMT1. It is characterized by severe intellectual disability,

hypotonia, cardiac defects, and characteristic facial features. 